\title{
RACHEL CARSON SALVA A BRANCA DE NEVE: PROPOSTA DE ESTRATÉGIA DIDÁTICA ENVOLVENDO O TEMA AGROTÓXICO NA EDUCAÇÃO BÁSICA
}

\author{
RACHEL CARSON SAVES SNOW WHITE: DIDACTIC STRATEGY PROPOSAL INVOLVING THE PESTICIDE \\ THEME IN BASIC EDUCATION
}

\section{RACHEL CARSON SALVA LA BLANCA NIEVE: PROPUESTA DE ESTRATEGIA DIDÁCTICA QUE INVOLUCRA EL TEMA AGROTOXICO EN LA EDUCACIÓN BÁSICA}

\author{
Lucas Peres Guimarães ${ }^{1 *}$ - iD \\ Tayná Gonçalves Silva ${ }^{2}-$ (iD) \\ Dimitri Ramos Alves ${ }^{3}$ - (iD)
}

\begin{abstract}
${ }^{1}$ Doutorando em Ensino de Ciências do Instituto Federal de Educação, Ciência e Tecnologia do Rio de Janeiro (IFRJ). Professor de Ciências da Secretaria Municipal de Educação de Barra Mansa, Rio de Janeiro, Brasil; ${ }^{2}$ Discente do curso de Ciências Biológicas do Centro Universitário de Volta Redonda (UNIFOA), Rio de Janeiro, Brasil; ${ }^{3}$ Doutor em Parasitologia, Professor do curso de Ciências Biológicas do Centro Universitário de Volta Redonda (UNIFOA), Rio de Janeiro, Brasil; * Autor correspondente: lucaspegui@,hotmail.com.
\end{abstract}

Recebido: 14/03/2021 | Aprovado: 31/03/2021 | Publicado: 06/04/2021

\begin{abstract}
Resumo: Os agrotóxicos são utilizados nas plantações agrícolas para o combate de pragas, que afetam diretamente a produção de alimentos no Brasil e no mundo. Porém, seus efeitos não se restringem às pragas, podendo causar danos ao ambiente e à saúde humana. Nesse sentido, objetivou-se propor uma sequência didática para o Ensino de Ciências, contextualizada no conto de fadas da Branca de Neve e os impactos dos agrotóxicos no meio ambiente, por meio da obra Primavera Silenciosa da bióloga Rachel Carson. Para possibilitar uma atividade lúdica apresentou-se a cartilha "A princesa, a maçã e os agrotóxicos" que relaciona os contos de fadas com o tema agrotóxicos e os impactos ambientais, a partir da proposta didática, que inclui questões relacionadas à história da ciência, na perspectiva política e social com o diálogo entre os Contos de Fadas e a Ciência. Para esse diálogo, a produção da atividade e sistematização dos saberes foram organizados em três esferas: Conceitual-fenomenológica, Histórico-metodológica e Sociopolítica. Dessa forma, conclui-se que a sequência didática possui potencial para o Ensino de Ciências, caracteriza-se como uma atividade lúdica que utiliza a criatividade e contribui para a formação de cidadãos críticos a respeito da problemática dos agrotóxicos.
\end{abstract}

Palavras-chave: Agrotóxicos. Contos de fadas. Educação básica. Ensino de Ciências. Estratégia didática.

\begin{abstract}
Pesticides are used in agricultural crops to combat pests, which directly affect food production in Brazil and worldwide. However, their effects are not restricted to pests, and can cause damage to the environment and human health. In this sense, we aimed to propose a didactic sequence for science teaching, contextualized in the fairy tale of Snow White and the impacts of pesticides on the environment, through the work Silent Spring by biologist Rachel Carson. To enable a playful activity, the booklet "The princess, the apple, and the pesticides" was presented. It relates the fairy tales with the theme pesticides and environmental impacts, from the didactic proposal, which includes issues related to the history of science, in the political and social perspective with the dialog between Fairy Tales and Science. For this dialogue, the production of the activity and the systematization of knowledge were organized in three spheres: Conceptualphenomenological, Historical-methodological, and Sociopolitical. Thus, it is concluded that the didactic sequence has potential for science teaching, is characterized as a playful activity that uses creativity and contributes to the formation of critical citizens regarding the problem of pesticides.
\end{abstract}

Keywords: Pesticides. Fairy tales. Basic education. Science teaching. Didactic strategy.

Resumen: Los plaguicidas se utilizan en las plantaciones agrícolas para combatir las plagas, que afectan directamente a la producción de alimentos en Brasil y en todo el mundo. Sin embargo, sus efectos no se limitan a las plagas y pueden causar daños al medio ambiente y a la salud humana. En este sentido, este estudio tuvo como objetivo proponer una secuencia didáctica para la Enseñanza de las Ciencias, contextualizada en el cuento de Blancanieves y los impactos de los pesticidas en el medio ambiente, a través de la obra Primavera Silenciosa de la bióloga Rachel Carson. Para posibilitar una actividad lúdica se presentó el cuaderno "La princesa, la manzana y los pesticidas" que relaciona los cuentos de hadas con el tema de los pesticidas y los impactos ambientales, a partir de la propuesta didáctica, que incluye temas relacionados con la historia 
de la ciencia, en perspectiva política y social con el diálogo entre los Cuentos de Hadas y la Ciencia. Para este diálogo, la producción de actividades y la sistematización del conocimiento se organizaron en tres ámbitos: conceptualfenomenológico, histórico-metodológico y sociopolítico. Así, se concluye que la secuencia didáctica tiene potencial para la enseñanza de la ciencia, se caracteriza por ser una actividad lúdica que utiliza la creatividad y contribuye a la formación de ciudadanos críticos sobre el problema de los pesticidas.

Palabras clave: Plaguicidas. Cuentos de hadas. Educación básica. Enseñanza de las ciencias. Estrategia didáctica.

\section{Introdução}

Em meados dos anos 60, as inovações na agricultura como a tecnologia de sementes, a fertilização do solo, a utilização de agrotóxicos e a mecanização agrícola para a obtenção de maior produtividade caracterizaram a Revolução Verde. Nesse contexto, os agrotóxicos são utilizados nas plantações agrícolas para o combate de pragas, que afetam diretamente a produção de alimentos no Brasil e no mundo. Porém, seus efeitos não se restringem às pragas, podendo causar danos ao ambiente e à saúde humana (Miranda et al., 2007).

O aumento da utilização de agrotóxicos nas plantações tem se mostrado um problema de ordem global e pouco problematizado nas mídias, especialmente na educação formal, nos diferentes níveis em que atua como relata Kugler (2012, p. 21):

\footnotetext{
O Brasil é a lixeira tóxica do planeta. Desde 2008, somos os maiores consumidores globais de insumos químicos para agricultura. Mas, diante de uma balança comercial envaidecida por números sedutores, discutir os reveses desse modelo agrário tornou-se tabu. A eterna e robusta economia agroexportadora, baseada em bens primários de baixo valor agregado, insiste em se reafirmar - ainda que assombrada por uma crise de percepção e acompanhada de temerosas dívidas sociais e ambientais.
}

O autor aponta ainda que o problema dos agrotóxicos é difícil de ser resolvido, e deve ser tratado em suas múltiplas dimensões já que tem um manejo complexo. Com base no exposto, as consequências do uso de agrotóxicos atingem tanto as pessoas que vivem no campo, os produtores, como as populações que vivem na cidade, ou seja, os consumidores.

De acordo com Rigotto \& Rosa (2012), diante do uso intenso de agrotóxicos no Brasil, é possível considerar que a maior parte da população está exposta a esses produtos de alguma forma. Os trabalhadores do campo são os que sofrem por mais tempo os efeitos desse produto, em seguida as comunidades que vivem próximas às plantações e por último, quem consome, ou seja, quase toda a população.

Um dos nomes mais emblemáticos em defesa da preservação da biodiversidade, é o da bióloga inglesa Rachel Carson (1907-1964). O seu livro Primavera Silenciosa (Carson, 2010), impactou toda a sociedade, com alertas acerca dos riscos causados pelos inseticidas, em especial do Dicloro Difenil Tricloroetano (DDT), utilizado abundantemente durante a Segunda Guerra Mundial. É relevante destacar que os trabalhos da autora foram essenciais para demonstrar a conexão entre os impactos ambientais e os seres humanos, que, de certa maneira, viabilizou a consolidação do ambientalismo moderno (Carson, 2010). O livro "Primavera Silenciosa" estabelece uma relação clara entre o perigo de pesticidas para o meio ambiente e biodiversidade do Planeta. Os 
acontecimentos retratados são reflexos do mundo moderno, bem como as contaminações provocadas pelos agentes químicos.

Diante do exposto, considera-se a importância do tema a ser tratado na Educação Básica (Guimarães \& Castro, 2020a), o que é ratificado pela Base Nacional Comum Curricular (BNCC) que nas habilidades no $9^{\circ}$ ano do Ensino Fundamental afirma que o estudante deve: “(EF09CI13) Propor iniciativas individuais e coletivas para a solução de problemas ambientais da cidade ou da comunidade, com base na análise de ações de consumo consciente e de sustentabilidade bem-sucedidas" (Brasil, 2017, p. 353).

Evidencia-se, assim, a necessidade ambiental e a responsabilidade social que todos têm de encarar a questão dos agrotóxicos, e isso passa por uma reflexão na sala de aula, na educação, tendo em vista que a escola é espaço de construção de conhecimentos e formação de cidadãos críticos e ativos para o enfrentamento dos problemas na sociedade (Guimarães \& Castro, 2020b).

Dessa forma, a interface do Ensino de Ciências e os Agrotóxicos estão majoritariamente aplicados em um contexto da educação no campo (Fernandes \& Stuani, 2015; Soares, Sanches \& Brito, 2018). Contudo, devese inserir a discussão também no meio urbano, ou seja, propor estratégias didáticas que possam sensibilizar os alunos da cidade quanto aos impactos ambientais dos agrotóxicos.

Sendo assim, a estratégia didática proposta neste trabalho será contextualizada com o conto de fadas da Branca de Neve por ser tradicional e ainda ocupar o imaginário de crianças e adultos, tendo em vista que a "A literatura é uma porta para a experimentação de um mundo novo por meio da palavra e da imaginação" (Avellar \& Couto, 2009, p. 31). As histórias permitem o jogo com as palavras e as imagens, e divertem, enquanto assimila a cultura e desenvolve a crítica, reflexão (Doran, 2005; Guimarães \& Castro, 2020a).

Desse modo, objetivou-se propor uma sequência didática para o Ensino de Ciências, contextualizada no conto de fadas da Branca de Neve sobre os impactos dos agrotóxicos no meio ambiente, por meio da obra Primavera Silenciosa da bióloga Rachel. A estratégia didática estabelece uma relação entre a personagem Branca de Neve e a cientista Rachel Carson, a partir do enxerto do conto de fadas em que a maçã é oferecida para a princesa. Pretende-se usar o conhecimento como o principal fator para a tomada de decisão dos estudantes com a utilização da proposta didática que conduz os alunos à releitura desse conto clássico, inserindo a temática dos agrotóxicos em discussão na educação básica.

\section{Material e métodos}

A estratégia didática proposta foi elaborada a partir da Pedagogia de Synders (2001), que considera a valorização da cultura primeira (uma cultura imediata), formada no dia a dia do educando, que tem legitimidade e efeito real de alegria e satisfação, entende-se que os contos de fadas como o da Branca de Neve e os Sete Anões, ocupam a cultura dos educandos, proporcionando diversão enquanto apreende os conceitos científicos. 
Salienta-se que a estratégia didática em questão não quer se restringir ao ensino de conceitos científicos, mas também abranger questões relacionadas com a história da ciência (Guimarães \& Castro, 2020a; Guimarães, 2020), incluindo os aspectos políticos e sociais. Dessa forma, a proposta de categorização dos saberes encontrase sistematizada em três esferas conforme Piassi, Gomes \& Ramos (2017), que contribuem para a organização de atividades que envolvam o diálogo, como entre o Conto de Fadas e as Ciências (Quadro 1).

Quadro 1 - Esferas conceituais em relação ao conteúdo epistemológico das ciências.

\begin{tabular}{|c|c|c|}
\hline Identificação & Tipo & Definição/Caracterização \\
\hline Esfera C & Esfera Conceitual-fenomenológica & $\begin{array}{l}\text { Elementos geralmente "vistos" como } \\
\text { conteúdo escolar, uma vez que são os } \\
\text { objetos próprios de estudo da Ciência. } \\
\text { São os próprios conceitos, fenômenos e } \\
\text { leis que categorizam essa esfera. }\end{array}$ \\
\hline Esfera $\mathrm{H}$ & Esfera Histórico-metodológica & $\begin{array}{l}\text { Inclui os métodos de estudo da Ciência e } \\
\text { a história de sua produção, envolvendo o } \\
\text { conhecimento da estrutura e do } \\
\text { funcionamento da prática científica. }\end{array}$ \\
\hline Esfera S & Esfera Sociopolítica & $\begin{array}{l}\text { Agrega as múltiplas interfaces entre } \\
\text { Ciência e sociedade, no âmbito cultural, } \\
\text { político, econômico e social, em ambos } \\
\text { os sentidos, ou seja, da sociedade para } \\
\text { Ciência e da Ciência para sociedade. }\end{array}$ \\
\hline
\end{tabular}

Fonte: adaptado de Piassi, Gomes \& Ramos (2017).

Assim sendo, o conto de fadas "Branca de Neve e os Sete Anões" será proposto a partir da releitura até o momento em que a maçã será oferecida para a princesa, ou seja, no clímax da história. Nesse momento, será trabalhada a Esfera C, relacionando o veneno da maçã com os agrotóxicos, a Esfera $\mathbf{H}$ quando é inserido as pesquisas e lutas de Rachel Carson contra os pesticidas, no livro "Primavera Silenciosa", em especial no primeiro capítulo denominado de "Fábula do Amanhã". A Esfera S será medida a partir da releitura do conto, em que serão discutidas as questões de gênero e a presença da mulher na ciência.

A metodologia para sala de aula aqui apresentada segue o roteiro sugerido por Piassi, Gomes \& Ramos (2017), constituído por três etapas: contextualização, apreciação coletiva e discussão coletiva.

$\mathrm{Na}$ etapa de Contextualização, as informações poderão ser introduzidas em relação ao momento do conto de fadas em que a Branca de Neve corre perigo, quando a rainha má oferece a maçã envenenada. Assim, será proposto aos alunos a inserção dos conhecimentos de Rachel Carson contra o uso de pesticidas. Pretendese levar os alunos à conclusão de que a Branca de Neve poderia ser salva utilizando as informações adquiridas ao ler a Obra da cientista, e não pelo príncipe, levando em conta a emancipação das mulheres, as lutas pela igualdade de gênero e equidade de decisões.

$\mathrm{Na}$ etapa da Apreciação coletiva, sugere-se que, em um primeiro momento, seja feita a leitura do conto de fadas e do capítulo "Fábula do Amanhã" que compõe o livro Primavera Silenciosa de Rachel Carson. Em seguida, para aperfeiçoamento da apreciação e início da discussão, sugere-se a seleção de trechos que estejam relacionados com o questionário elaborado. A reexibição de trechos se justifica por dois motivos: permite aos 
alunos que faltaram no momento da leitura carrossel possam se integrar na discussão dos tópicos propostos e possibilitar a análise dos detalhes das cenas que possam ter passado despercebidos.

Para apreciação coletiva do conto da Branca de Neve e a leitura do primeiro capítulo "Fábula do Amanhã” do livro Primavera Silenciosa de Rachel Carson, sugere-se a utilização da metodologia ativa Carrossel para leitura dos textos. Essa proposta metodológica consiste em fazer rodas de discussões sobre o tema abordado e baseia-se nos passos descritos a seguir:

- Rodada 1 - divisão do texto em X partes e dos alunos em X grupos, ficando uma parte do texto para cada grupo de alunos. Cada grupo lê a parte que foi designada pelo mediador;

- Rodada 2 - após a leitura, um representante do Grupo 1 é direcionado para o Grupo 2, um representante do Grupo 2 para o Grupo 3, e assim por diante, o representante do último grupo irá para o Grupo 1;

- Rodada 3 - o representante do Grupo 1 que estava no Grupo 2 se direciona para o Grupo 3, já o representante do Grupo 2, que estava no Grupo 3, se direciona para o Grupo 4, e assim por diante, e o representante do último grupo que estava no Grupo 1 se direciona para o Grupo 2;

- Rodada X+1 - repetem-se os procedimentos anteriores até que o representante do Grupo 1 retorne ao Grupo 1, o do Grupo 2 retorne ao Grupo 2, etc.; o representante contará as partes que recolheu dos demais colegas na ordem da narrativa, isto é, primeiro a parte 1 , depois a parte $2, \ldots$, até finalizar o texto.

O uso de questionários durante a apreciação coletiva permite despertar a criatividade e fazer descobertas no campo das ciências, mas para esses tipos de questões é importante dar tempo aos alunos para reflexão e busca de informações sobre a temática. No entanto, em tempos das Fakes News, faz-se necessário que essa discussão retorne à sala de aula a fim de que as informações sejam compartilhadas e certificadas.

Para reforçar a apreciação do texto, após a leitura pela metodologia Carrossel, é a resolução de questões que abranja tantos aspectos da esfera conceitual-fenomenológica quanto da esfera sociopolítica. Essas questões também servirão para nortear a próxima etapa: a Discussão coletiva

Quanto às questões para discussão coletiva, sugerimos a que estão transcritas a seguir:

1. Quais são as principais diferenças do conto da Branca de Neve que lemos e do filme da Disney?

2. Analise criticamente o papel do príncipe na história.

3. Existem maçãs envenenadas hoje em dia?

4. Quais contribuições Rachel Carson poderia passar para a Branca de Neve se a conhecesse?

5. Rachel Carson escreveu a Primavera Silenciosa há muito tempo, você percebe alguma mudança nos dias atuais a partir das reflexões do trabalho dessa cientista?

6. Na história, aprendemos como minimizar os pesticidas, através de métodos de higienização utilizando a prática de Agroecologia. Com essas informações, compartilhe com a sala se já presenciou casos de alimentos contaminados em ambientes comerciais. 
7. Rachel Carson foi uma importante cientista mulher na luta contra os pesticidas. Pesquise e compartilhe com a sala outras cientistas mulheres e suas contribuições para a construção de conhecimento científico.

Com o objetivo de relacionar o trabalho de Rachel Carson com a personagem Branca de Neve, produziu-se uma cartilha para ser utilizado com os alunos na aplicação da estratégia didática proposta, com a finalidade de tornar o ensino do tema agrotóxico mais lúdico para os estudantes (Figura 1).

Figura 1 - Capa da cartilha "A princesa, a maçã e os agrotóxicos" para utilização no Ensino de Ciências.

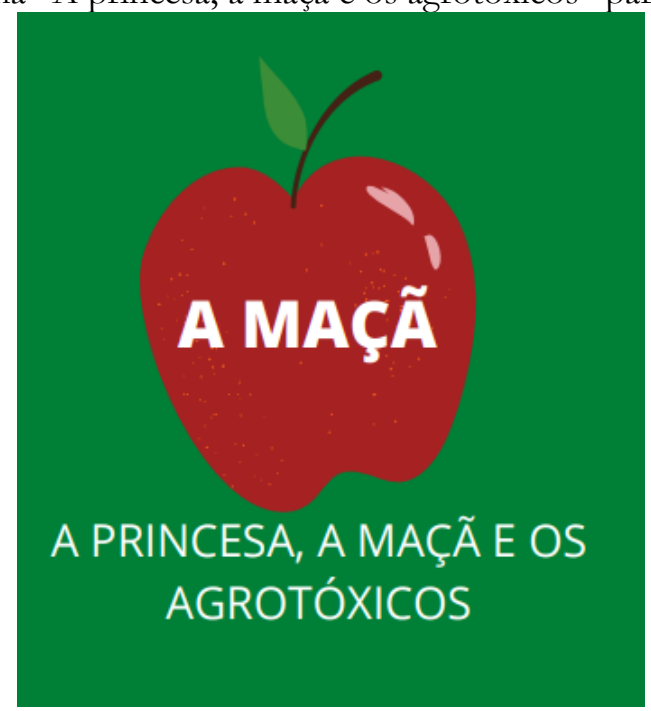

Fonte: Autores, 2021.

Apesar do conto de fadas "Branca de Neve e os sete anões" ser uma obra clássica, abre caminho para abordar de forma lúdica os conhecimentos de Rachel Carson contra o uso dos pesticidas. Ao lançar o olhar para a parte da história em que a maçã envenenada é oferecida a Branca de Neve, permite-se a preparação de projetos interdisciplinares que introduzam conceitos de Biologia na educação básica.

A utilização da cartilha torna-se um recurso capaz de explorar vários instrumentos de multimídia, apesar desses dispositivos estarem presentes no cotidiano dos estudantes, essa modalidade otimiza e amplia o aprendizado, além de aumentar o envolvimento narrativo e estimular o leitor a imaginar.

\section{Resultados e discussão}

É notório a distância entre as instituições de Ensino Superior e a Escola de Educação Básica. Uma das maneiras de aproximar o conhecimento produzido nos bancos acadêmicos e a escola básica é por meio dos chamados Produtos Educacionais (Moreira, 2004). No entanto, não se pretende que a estratégia proposta nesta pesquisa seja comparada com as produzidas em cursos de Pós-Graduação, mas entende-se que a disponibilização de uma cartilha (https://educapes.capes.gov.br/handle/capes/584895) como parte integrante desse trabalho facilita o acesso dos professores e a utilização no Ensino de Ciências. 
A escolha do conto de fadas “A Branca de Neve e os Sete Anões” deve-se ao fato de que essa história ocupa o imaginário de qualquer idade, a literatura, ainda mais os contos de fadas "e uma porta para a experimentação de um mundo novo por meio da palavra e da imaginação" (Avellar \& Couto, 2009, p. 31).

Ensinar ciências de forma isolada sem considerar os múltiplos contextos é algo que a proposta didática busca repensar com o docente de ciências, então a inserção de um pequeno trecho do conto da Branca de Neve almeja motivar os alunos para o conhecimento sobre os agrotóxicos (Figura 2).

Figura 2 - Trecho do conto de fadas trabalhado na proposta didática.

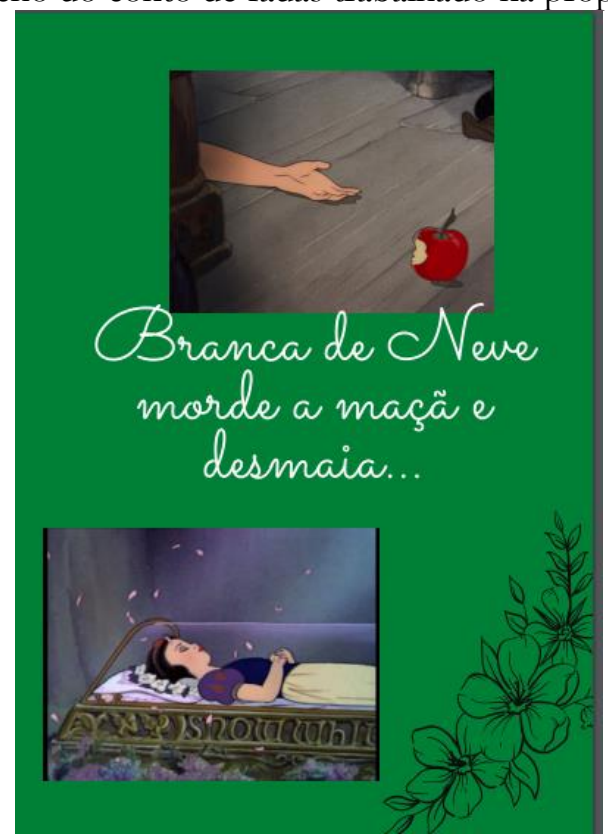

Fonte: Autores, 2021.

Os contos de fadas permitem ir além da imaginação, assim, é importante que o aluno se encante com o conhecimento científico a ser explorado, mas como inserir o conceito de agrotóxico que essa proposta didática apresenta?

Nesse sentido, os professores podem convidar os alunos a fazerem uma reescrita da história do conto de fadas a partir dos saberes da bióloga Rachel Carson (Figura 3). A inserção dessa cientista representa na história o encontro da Branca de Neve com o conhecimento científico que Carson divulgou com seu livro Primavera Silenciosa. 
Figura 3 - Rachel Carson sendo apresentada na cartilha "A princesa, a maçã e os agrotóxicos".

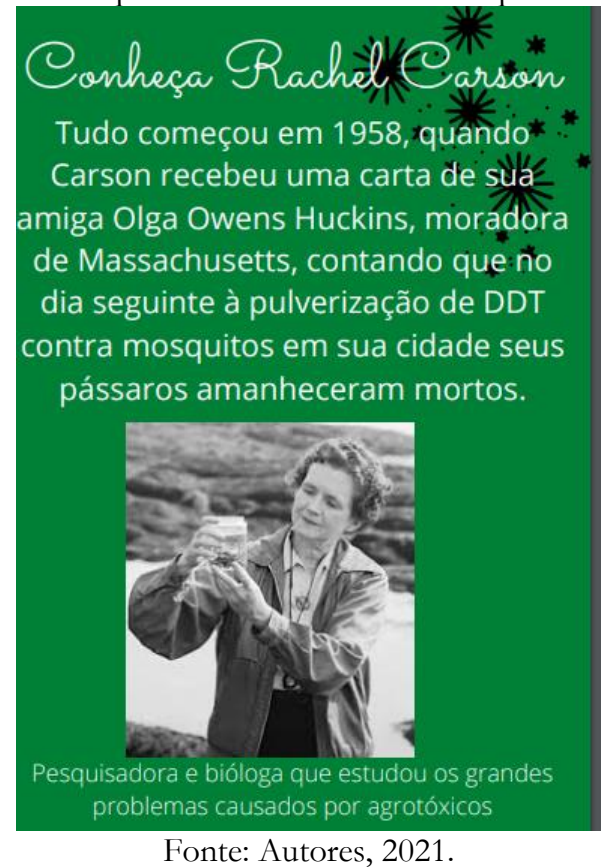

A luta ambiental contra os pesticidas e o enxerto da história da Branca de Neve introduz o aluno em uma discussão mundial sobre os limites do uso dos agrotóxicos na alimentação, e os danos potenciais à saúde humana e interferência na qualidade ambiental. Isso acontece pela união do lúdico ao Ensino de Ciências, demonstrando uma forma mais próxima e interessante para o aluno ao estudar o conteúdo, já que muitos deles estão no meio urbano.

Espera-se que com a interseção dessas duas histórias, o aluno possa fazer uma reescrita do desenrolar do conto de fadas em que o conhecimento científico poderá mudar a sequência dos fatos, considerando através de suas análises, propostas individuais e coletivas para o problema ambiental discutido (uso dos agrotóxicos) e para outros problemas. Desse modo, essa proposta didática corresponderá a habilidade da BNCC que se propõe a cumprir que é levar o aluno a: "(EF09CI13) Propor iniciativas individuais e coletivas para a solução de problemas ambientais da cidade ou da comunidade, com base na análise de ações de consumo consciente e de sustentabilidade bem-sucedidas". (Brasil, 2017, p. 353).

Apesar da relevância das discussões a respeito dos agrotóxicos, nem sempre esse debate ocorre na educação básica, quando aparece é comum ser de forma sintética. Assim, a proposta da cartilha, possibilita rememorar a obra de Rachel Carson e abordar o tema de modo lúdico, por meio do conto de fadas mostrando uma visão contextualizada da utilização dos agrotóxicos e os efeitos nas plantações e na sociedade (Figura 4).

$\mathrm{Na}$ estratégia didática em questão considera-se as esferas estabelecidas por Piassi, Gomes \& Ramos (2017) com a Esfera Conceitual-fenomenológica (Esfera C): Elementos geralmente "vistos" como conteúdo escolar, uma vez que são os objetos próprios de estudo da Ciência, a esfera Histórico-metodológica (Esfera H): Inclui os métodos de estudo da Ciência e a história de sua produção, envolvendo o conhecimento da estrutura e do funcionamento da prática científica e a esfera Sociopolítica (Esfera S): Agrega as múltiplas interfaces entre 
Ciência e sociedade, no âmbito cultural, político, econômico e social, em ambos os sentidos, ou seja, da sociedade para Ciência e da Ciência para sociedade.

Figura 4 - Branca de Neve e Rachel Carson, o diálogo.

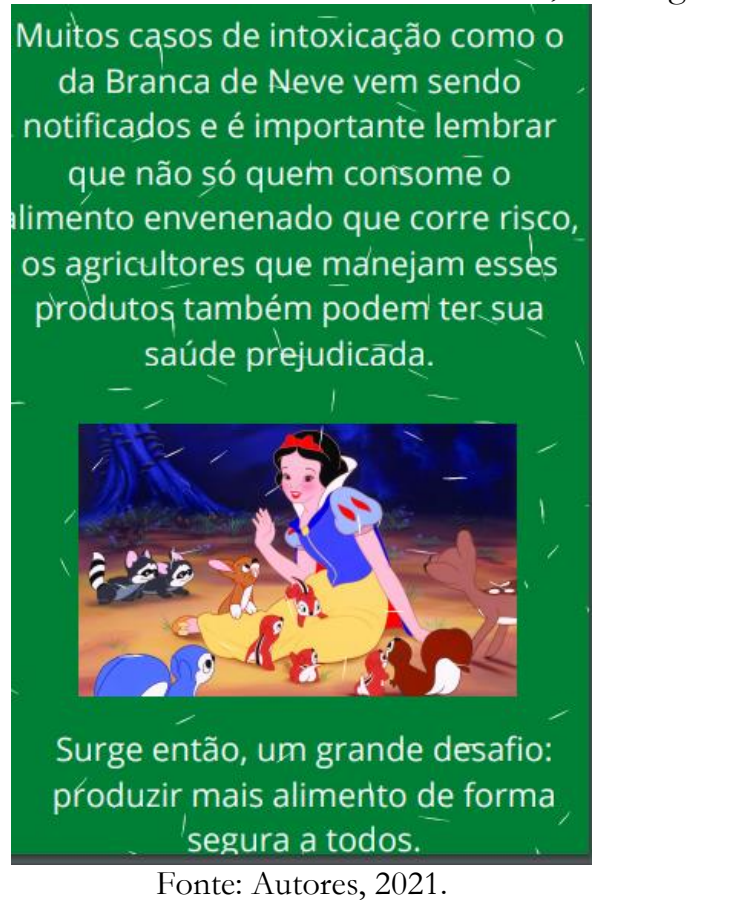

Pela razão do uso de agrotóxicos impactar o meio ambiente e a saúde humana, é importante que essa temática, inclusive na escola, seja avaliada por diferentes olhares disciplinares. Assim, a inserção da estratégia didática proporciona uma aproximação interdisciplinar do Ensino de Ciências com a literatura clássica de conto de fadas, de modo a contribuir para o processo de ensino e aprendizagem, com ampliação de conhecimentos e discussões da temática na sociedade, tornando os estudantes cidadãos ativos.

$\mathrm{Na}$ busca da inserção do conhecimento científico no cotidiano dos alunos, foram propostas oficinas de agroecologia no final da cartilha, com procedimentos simples que possam ser reproduzidos em sala de aula, por exemplo quando forem se alimentar de frutas, como a personagem do conto de fadas, discutir os efeitos dos agrotóxicos nesses alimentos (Figura 5). 
Figura 5 - Parte da Cartilha “A princesa, a maçã e os agrotóxicos” em que se inicia as oficinas de agroecologia.

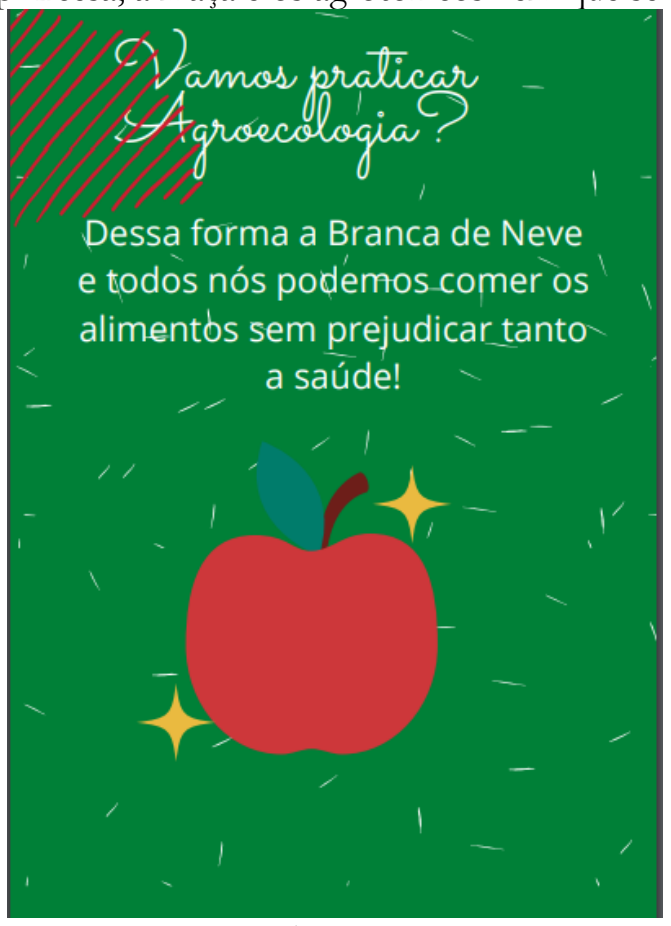

Fonte: Autores, 2021.

Por fim, a temática dos agrotóxicos possibilita uma abordagem interdisciplinar e integrada com os conteúdos de diferentes áreas do conhecimento, de forma a proporcionar a compreensão de problemas vinculados à realidade dos alunos, fazendo uma junção da proposta didática na educação. Dessa forma, reforça a necessidade de os processos educativos formais retratar a problemática dos agrotóxicos, com intuito de formar cidadãos mais conscientes com essa questão na sociedade contemporânea.

\section{Considerações finais}

Embasado na estratégia didática proposta por meio da cartilha "A princesa, a maçã e os agrotóxicos", sugere-se que os alunos façam uma leitura para desenvolver seus próprios conhecimentos a respeito da temática, além de interpretar o conto de fadas da Branca de Neve e os Setes Anões com as informações aprendidas na obra Primavera Licenciosa, em que a abordagem da autora Rachel Carson fortifica a importância da valorização da problematização do uso intensivo de agrotóxicos e também a valorização das lutas das mulheres pela igualdade de gênero na ciência.

Nesse contexto, o principal elemento utilizado é o conhecimento para que os próprios alunos tomem decisões com base em informações, proporcionando entretenimento enquanto aprende. A metodologia de elaboração da proposta didática consiste em fazer rodas de discussões para estimular a capacidade de processamento de informações e construção de argumentos com base nas informações passadas em cada grupo durante a aula. Isso desencadeia o poder de decisão, análise, posicionamento crítico e prática social perante temas que interferem em suas vidas. 
Embora a temática dos agrotóxicos seja considerada tema social e científico, é fundamental abordar visões, contextualizá-las e aprender suas apropriações e finalidades a respeito do tema. Portanto, podem ser observados por diferentes lentes teóricos e metodológicos, como por exemplo, a educação ambiental e referenciais ligados à perspectiva freiriana de educação e outras analíticas críticas.

A temática dos agrotóxicos pode ser discutida por diferentes estratégias didáticas e em diversas áreas do conhecimento. No Ensino de Ciências podem ser explorados aspectos ligados aos conteúdos conceituais e de cunho social, ambiental, político, econômico, histórico e ético, como também, outros igualmente importantes para formar cidadãos críticos e ativos na sociedade como proposto na cartilha desenvolvida.

\section{Conflitos de interesses}

Os autores declaram que não há conflitos de interesse. Todos os autores estão cientes da submissão do artigo.

\section{Referências}

Avellar, G. C.; \& Couto, R. C. O. (2009). Literatura infantil e a formação do leitor: a utilização dos clássicos adaptados no ensino fundamental I e II. Dialógica, 8(1),27-34.

Brasil (2017). Competências especificas de Ciências da Natureza para o Ensino Fundamental. Base Nacional Comum Curricular. Brasília: MEC.

Carson, R. (2010). Primavera Silenciosa. São Paulo: Gaia.

Doran, R. (2005). Um exame crítico do uso da literatura de contos de fadas com crianças pré-primárias em programas de educação e cuidados infantis apropriados ao desenvolvimento. In Schonfield, H.; O’Brien, S.; Walsh, T. (Eds.). Questões de qualidade: anais de uma conferência sobre definição, avaliação e apoio à qualidade na atenção e educação na primeira infância. Dublin: Centro para a Primeira Infância e Desenvolvimento e Educação. p.63-9.

Fernandes, C. S.; \& Stuani, G. M. (2015). Agrotóxicos no Ensino de Ciências: uma pesquisa na educação do campo. Educação \& Realidade, 40(3), 745-762.

Guimarães, L. P. (2020) A incorporação da história da ciência no ensino para a discussão dos raios-x na educação básica. História da Ciência e Ensino: Construindo Interfaces, 22, 148-161.

Guimarães, L. P.; \& Castro, D. L. (2020a). História da química como caminho para discussão da mulher na ciência. Dynamis (FURB. Online), 26, 122-135.

Guimarães, L. P. \& Castro, D. L. (2020b). Visão dos professores de ciências da rede municipal de Barra Mansa, diante dos desafios da Base Nacional Comum Curricular (BNCC). Horizontes - Revista de Educaşão, 8, 6-19.

Kugler, H. (2012). Paraíso dos Agrotóxicos. Ciência Hoje, 296(50), 20-25.

Miranda, A. C.; Moreira, J. C.; Carvalho, R.; \& Peres, F. (2007). Neoliberalismo, uso de agrotóxicos e a crise da soberania alimentar no Brasil. Revista Ciência e Saúde Coletiva, 12(1), 7-14. 
Moreira, M. A. (2004). O mestrado (profissional) em ensino. Revista Brasileira de Pós-Graduação. 1(1), 131-142.

Piassi, L. P. C.; Gomes, E. F.; \& Ramos, J. E. F. (2017). Literatura e cinema no ensino de física: interfaces entre a ciência e a fantasia. (1. ed.). São Paulo: Editora Livraria da Física.

Rigotto, R. M.; \& Rosa, S. F. (2012) Agrotóxicos. In: Caldart, R. et al. (Org.). Dicionário de educação do campo. São Paulo: Expressão Popular. 86-94.

Soares, P. R. L.; Sanches, A. W.; \& Brito, F; de A. A. (2018). A Primavera Silenciosa de Rachel Carson no Ensino de Quimica: um relevante instrumento para promoção da educação ambiental. Anais V CONEDU... Campina Grande: Realize Editora.

Snyders, G. (2001). Para onde vão as pedagogias não-diretivas? (3. ed.) São Paulo: Centauro.

\section{Contribuições dos autores}

Lucas Peres Guimarães - Coorientador da proposta e desenvolveu em conjunto com a discente Tayná todo o aporte teórico e a linha de abordagem delineada.

Tayná Gonçalves Silva - Discente do curso de Ciências Biológicas do UNIFOA e utilizou parte dessa proposta como seu trabalho de conclusão de curso, seguindo orientações prévias e desenvolvendo a cartilha

Dimitri Ramos Alves - Orientador da pesquisa e docente do curso de Ciências Biológicas do UNIFOA, foi responsável pela revisão técnica e teórica.

Todos os autores revisaram e aprovaram a versão final do manuscrito. 